\title{
A candidate RxLR effector from Plasmopara viticola can elicit immune responses in Nicotiana benthamiana
}

\author{
Jiang Xiang ${ }^{1,2}$, Xinlong Li', Ling Yin ${ }^{3}$, Yunxiao Liu', Yali Zhang ${ }^{1}$, Junjie $\mathrm{Qu}^{3}$ and Jiang $\mathrm{Lu}^{1,2,3^{*}}$
}

\begin{abstract}
Background: Diverse plant pathogens deliver effectors into plant cells to alter host processes. Oomycete pathogen encodes a large number of putative RxLR effectors which are likely to play a role in manipulating plant defense responses. The secretome of Plasmopara viticola (downy mildew of grapevine) contains at least 162 candidate RxLR effectors discovered in our recent studies, but their roles in infection and pathogenicity remain to be determined. Here, we characterize in depth one of the putative RxLR effectors, PvRxLR16, which has been reported to induce cell death in Nicotiana benthamiana in our previous study.

Results: The nuclear localization, W/Y/L motifs, and a putative N-glycosylation site in C-terminal of PvRxLR16 were essential for cell death-inducing activity. Suppressor of G-two allele of Skp1 (SGT1), heat shock protein 90 (HSP90) and required for Mla12 resistance (RAR1), but not somatic embryogenesis receptor-like kinase (SERK3), were required for the cell death response triggered by PvRxLR16 in N. benthamiana. Some mitogen-activated protein kinases and transcription factors were also involved in the perception of PVRXLR16 by N. benthamiana. PVRxLR16 could also significantly enhance plant resistance to Phytophthora capsici and the nuclear localization was required for this ability. However, some other PvRxLR effectors could suppress defense responses and disease resistance induced by PvRxLR16, suggesting that it may not trigger host cell death or immune responses during physiological infection under natural conditions.
\end{abstract}

Conclusion: These data demonstrate that PVRxLR16 may be recognized by endogenous proteins in nucleus to trigger immune responses in $\mathrm{N}$. benthamiana, which in turn can be suppressed by other PVRxLR effectors.

Keywords: Plasmopara viticola, grapevine, RxLR effector, Nicotiana benthamiana cell death, immune responses

\section{Background}

In nature, plants are attacked by various pathogens and protect themselves via sophisticated surveillance systems of innate immunity [1-3]. The first layer of the plant immune system is known as PAMP-triggered immunity (PTI) and has evolved to detect evolutionarily conserved molecular signatures of pathogens (pathogen- or microbeassociated molecular patterns (PAMPs/ MAMPs) and PRR-mediated immunity) $[4,5]$. In turn, successful pathogens can secrete effector proteins into host cells to

\footnotetext{
* Correspondence: Jiang.lu@sjtu.edu.cn

${ }^{1}$ The Viticulture and Enology Program, College of Food Science and Nutritional Engineering, China Agricultural University, Beijing, China ${ }^{2}$ Center for Viticulture and Enology, School of Agriculture and Biology, Shanghai Jiao Tong University, Shanghai 200240, China

Full list of author information is available at the end of the article
}

interfere with PTI, resulting in effector-triggered susceptibility (ETS). The second layer of the plant immune system is effector-triggered immunity (ETI), whereby plant resistance $(\mathrm{R})$ proteins recognize pathogen effectors directly or indirectly, resulting in localized cell death known as the hypersensitive response (HR). These effector proteins recognized by $R$ gene products of host plants are proposed to be avirulence (Avr) proteins $[4,6,7]$.

Oomycetes are a major class of destructive plant pathogens, which contain over 800 species of downy mildew pathogens in 17 genera (Peronosporaceae), along with over 120 species in the Phytophthora genus $[8,9]$. Oomycetes also deliver a wide diversity of effectors into plant cells to subvert host immunity as other pathogens [10]. To date, increasing numbers of Avr genes have 
been identified from different oomycetes, including Phytophthora sojae, Phytophthora infestans and Hyaloperonospora arabidopsidis [11-24]. Interestingly, all the Avr proteins from oomycetes, with one exception (ATR5), contain an $\mathrm{N}$-terminal signal peptide which can direct the effector to the outside of the pathogen, followed by RxLR-EER motifs that are responsible for transporting effector into the interior of host cells $[23,25]$. These effectors carrying RxLR motifs are defined as RxLR effectors which have been extensively studied in recent years [26]. The important discovery of RxLR effectors in oomycetes has expedited the identification process of avirulence genes [12].

Emerging evidences indicate that RxLR effectors target various subcellular compartments of plant cells to perform their functions. For instance, the effector Avh241 of $P$. sojae localizes to plasma membrane and the localization is required for its activity to induce cell death [27]. Functional analysis revealed the $H$. arabidopsidis effector HaRxL17 significantly enhances plant susceptibility which localizes to the tonoplast in uninfected cells and to membranes around haustoria in infected cells [28]. In another study, it was found that the effector AVRblb2 from $P$. infestans accumulates around haustoria and enhances susceptibility of hosts by preventing the host papain-like cysteine protease C14 secreting into the apoplast [29]. Similarly, the P. infestans RxLR effector AVR2 accumulates around haustoria with its host target BSL1, a putative phosphatase, to promote the association of BSL1 with R2, thereby triggering HR [30]. The plant cell nucleus is also considered one of the main targets for RxLR effector proteins. Many recent studies on interactions between plants and oomycete pathogens indicated that RxLR effectors target the host nucleus in order to modify host cell physiology. RxLR effector Pi04089 from the potato blight pathogen $P$. infestans localizes to host nucleus where it targets the putative potato K-homology (KH) RNAbinding protein, StKRBP1, to enhance colonization. Its nuclear localization is required for enhanced colonization of P. infestans [31]. Pi04314, another RxLR effector from $P$. infestans, also accumulates in the host nucleus and has the ability to impair induction of jasmonic and salicylic acid-responsive genes to enhance leaf colonization by $P$. infestans [32].

The hypersensitive response (HR)-like cell death is one of the most dramatic displays of programmed cell death (PCD) that is frequently observed in ETI [33]. Some host immune responses precede the HR in general, including proteolysis, changes in ion fluxes, accumulation of reactive oxygen species (ROS), increased levels of defense- related hormones, and activation of mitogen-activated protein kinase (MAPK) cascades [34]. The timely induction of HR in host plants seems to establish a formidable barrier to pathogen colonization, especially to biotrophic organisms which must absorb nutrients from living host cells. For example, ATR1, an avirulence protein of $H$. arabidopsidis, can elicit HR and a resistance response to pathogens in the presence of RPP1 [23]. Moreover, the avirulence effector AVR1 of $P$. infestans activates R1mediated hypersensitive response and host defence when the AVR1/R1 pair is in the nucleus [35]. PAMPs may also elicit programmed cell death when recognized by pattern recognition receptors (PRRs) directly or indirectly. The PcINF1 elicitin from P. capsici, conceived as oomycete PAMPs, triggers cell death in pepper (Capsicum annuиm L.), apparently by binding to a cell surface receptor SRC2-1 [36].

The obligate biotrophic oomycete Plasmopara viticola ([Berk. et Curt.] Berl. et de Toni) causes devastating downy mildew disease of grapevine all over the world. This pathogen needs to obtain all of its nutrition from living cells of grapevine to complete its whole life cycle [37]. However, the molecular basis of the interaction between $P$. viticola and the grapevine host is not well understood. Currently, a secretome of grapevine downy mildew was predicted by transcriptome sequencing analysis and then 51 RxLR effector candidates were identified [38]. Interestingly, one of these effectors, PvRxLR16, could directly trigger cell death in $N$. benthamiana which was highly expressed at the late infection stages (72 hpi). However, many other PvRxLR effectors fully blocked the programmed cell death elicited by PvRxLR16 [39]. Functional verification of this effector is of particular interest for the identifying potential virulence or avirulence factor.

In the present study, we aimed to further characterize the function of the effector protein PvRxLR16 in $N$. benthamiana. Sequence analysis revealed the presence of W/Y/L motifs and a putative $N$-glycosylation site. Deletions or mutations on these motifs abolished the cell death inducing activity of PvRxLR16. Some key proteins involved in signaling pathways of immunity were essential for the cell death response triggered by PvRxLR16. In addition to cell death, PvRxLR16 could elicit other basal defence responses, including ROS accumulation and defence-associated genes expression, resulting in disease resistance of $N$. benthamiana against $P$. capsici. However, the immune responses triggered by PvRxLR16 could be abolished successfully by other RxLR effectors from $P$. viticola.

\section{Methods}

\section{Plant material and growth condition}

Seeds of Arabidopsis thaliana (Col-0) purchased from The Arabidopsis Information Resource (TAIR) were cultivated in a phytochamber at $22{ }^{\circ} \mathrm{C} / 16 \mathrm{~h}$ light and $20{ }^{\circ} \mathrm{C} / 8 \mathrm{~h}$ dark cycle under $40 \%-60 \%$ humidity. Nicotiana benthamiana plants (provided by Prof. Guiqin Qu from China Agricultural University) were grown in a 
greenhouse at $25{ }^{\circ} \mathrm{C}$ with $16 \mathrm{~h}$ of illumination per day. Onion (Allium cepa L.) was purchased from a local supermarket.

\section{Plasmid construction}

The primers used for the following plasmid constructs are shown in Supporting Information Additional file 1: Table S1. The various mutants of $P v R x L R 16$ for PVX assay were amplified using combinations of primers documented in Additional file 1: Table S1. The PCR products were cut with Xma I and Sal I restriction enzymes and ligated into the PVX::flag vector. For GFP fusion constructs, $P v R x L R 16, P v R x L R 16: N E S$ and $P v R x$ LR16:nes were amplified with gene-specific primers modified to contain the Gateway (Invitrogen) attB recombinantion sites. The PCR amplicons were cloned into entry vector pDONR222 (Invitrogen) via $\mathrm{BP}$ reactions and subsequently recombined into the binary vector pH7FWG2, 0 using Gateway LR recombination. To make the constructs for virus induced gene silencing (VIGS) in N. benthamiana, partial sequences of purpose genes were amplified from cDNA of $N$. benthamiana and subsequently ligated into pTRV2 vector using the Xma I and Kpn I restriction sites. All the generated plasmids were validated by sequencing by Majorbio, Inc. (Shanghai, China). The schematic diagrams of constructs used in this study were shown in Additional file 2: Figure S1.

\section{Agroinfiltration and infection assays}

Agroinfiltration assays in $N$. benthamiana were performed as described in our previous study [39]. Infection assays were performed by droplet inoculation of zoospore suspensions (100 of zoospores/ $\mu \mathrm{L}$ ) on detached N.benthamiana leaves. Zoospores were prepared as reported previously [40]. Agrobacteria (provided by Prof. Daolong Dou, Nanjing Agricultural University) cells containing plasmid constructs were infiltrated in N.benthamiana leaves. After $24 \mathrm{~h}$, each leave was detached and inoculated with zoospore suspensions on the abaxial surface. The diameters of the infected areas were measured at 36 and $48 \mathrm{hpi}$, and photographed at $36 \mathrm{~h}$ under UV light. Data of at least three biological replicates were combined.

\section{Protoplast preparation of $A$. thaliana and transfection}

The isolation of $A$. thaliana mesophyll protoplasts and polyethylene glycol- mediated transfection were performed as described in previous [41]. Briefly, wellexpanded leaves were cut into $0.5-1 \mathrm{~mm}$ leaf strips and dipped into enzyme solution containing $1.5 \%$ cellulose 'Onozuka' R10 and 0.4\% macerozyme R10 (Yakult Pharmaceutical). After $30 \mathrm{~min}$ vacuum-infiltration and $3 \mathrm{~h}$ digestion at room temperature in the dark, the enzyme-protoplast mixture was filtered with 75-mm nylon mesh. Subsequently, protoplasts were washed twice with W5 buffer and suspended in MMG buffer to a density of $2 \times 10^{5}$ cells $/ \mathrm{ml} .10 \mu \mathrm{g}$ plasmid and $100 \mu \mathrm{L}$ protoplast suspension were used per reaction of transfection. Then the transfection process was stopped with W5 buffer. Finally, protoplasts were incubated in W1 buffer at room temperature in the dark for $12-16 \mathrm{~h}$ for gene expression.

\section{Particle bombardment assays}

The plasmid of PvRxLR16 fused with GFP and the GFP vector were mixed with gold power (Bio-Rad, USA), respectively. And then they were transformed into onion epidermal cells using a $\mathrm{He} / 1000$ particle delivery system (Bio-Rad, USA) at 1100 psi as described by Mare et al. [42]. The onion epidermal cells were cultured in Murashige-Skoog (MS) media in darkness at $21{ }^{\circ} \mathrm{C}$ for $18 \mathrm{~h}$ before observation.

\section{Confocal microscopy}

Patches were cut from onion epidermal cells and agroinfiltrated $N$. benthamiana leaves. Then microscope slides carrying the patches and Arabidopsis protoplasts were imaged using a Nikon C1 Si/TE2000E confocal laser scanning microscope. The excitation and emission wavelengths for GFP were $488 \mathrm{~nm}$ and 505-530 nm, respectively.

\section{VIGS Assays in N. benthamiana}

Agrobacterium strains harboring pTRV1 and pTRV2gene were grown overnight in LB containing appropriate antibiotics, harvested, suspended in infiltration medium $\left[10 \mathrm{mM} \mathrm{MgCl}_{2}, 10 \mathrm{mM}\right.$ MES (pH 5.7) and $200 \mu \mathrm{M}$ acetosyringone], mixed in a $1: 1$ ratio to an $\mathrm{OD}_{600}=0.5$ for each strain. The cocultures were then infiltrated using needless syringes on the abaxial side of 3-week-old leaves of $N$. benthamiana. The agroinfiltrated plants were then grown for about 3 weeks before cell death assay. Gene silencing levels were checked by quantitative reverse transcription (RT)-PCR.

\section{RNA extraction and real time quantitative RT-PCR}

Total RNA of $N$. benthamiana leaves was isolated using a commercial kit (RNA simple Total RNA Kit, Tiangen) following the recommended protocols. All cDNA synthesis and quantitative RT-PCR reactions were performed according to previous methods [43]. The EF1 $\alpha$ gene from $N$. benthamiana was used as an internal reference gene to determine relative expression values. Primers were designed by primer 5.0 software (PREMIER Biosoft International, Canada) with the default settings. 


\section{Protein extraction and Western blot}

Agroinfiltrated $N$. benthamiana leaves were harvested at $2 \mathrm{dpi}$ and homogenized in liquid nitrogen. And then protein extraction buffer $(1 \mathrm{~mL})$ containing $50 \mathrm{mM} 4-(2-$ hydroxyethyl)-1-piperazineëthanesulfonic acid (HEPES), $150 \mathrm{mM} \mathrm{KCl}, 1 \mathrm{mM}$ ethylenediaminetetraacetate (EDTA) $(\mathrm{pH} 8.0), \quad 0.1 \%$ triton $\mathrm{X}-100,1 \mathrm{mM}$ dl-dithiothreitol (DTT), and $1 \times$ Protease Inhibitor Cocktail (Sigma) was added to $500 \mathrm{mg}$ of each ground sample. The samples were mixed and centrifuged at $12000 \mathrm{rpm}$ for $15 \mathrm{~min}$ at $4{ }^{\circ} \mathrm{C}$. Supernatants were separated by $12 \%$ sodium dodecyl sulfate-polyacrylamide gel electrophoresis (SDS-PAGE) and transferred to a nitrocellulose blotting membrane. Western blot analysis was conducted using an anti-cFlag peroxidase conjugate (Sigma- Aldrich).

\section{Trypan blue staining}

Cell death in $N$. benthamiana leaves was examined by using trypan blue staining. Agroinfiltrated leaves were harvested at $2.5 \mathrm{dpi}$ and soaked in boiling trypan blue

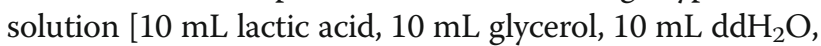
$10 \mathrm{~g}$ phenol and $20 \mathrm{mg}$ trypan blue (Sigma-Aldrich)] for $5 \mathrm{~min}$ and incubated for $3 \mathrm{~h}$. Samples were then decolorized in $2.5 \mathrm{~g} / \mathrm{mL}$ chloral hydrate solution to clear the background and photographed.

\section{Oxygen burst detection}

Oxygen burst was detected according to $\mathrm{H}_{2} \mathrm{O}_{2}$ accumulation after staining $N$. benthamiana leaves with 3, 3'diaminobenzidine (DAB) [44]. Briefly, Agroinfiltrated $N$. benthamiana leaves were detached at $72 \mathrm{hpi}$. Then the leaves were soaked in DAB solution $\left(1 \mathrm{mg} / \mathrm{mL} \mathrm{ddH}_{2} \mathrm{O}\right)$ and maintained for $8 \mathrm{~h}$ at $25{ }^{\circ} \mathrm{C}$. The leaf tissues were cleared by boiling in $95 \%$ ethanol for 15 min until all the chlorophyll was entirely bleached. The blenched samples were then soaked in trichloracetic aldehyde solution at $2.5 \mathrm{~g} / \mathrm{mL}$ to further remove the background. The $\mathrm{H}_{2} \mathrm{O}_{2}$ levels were quantified by Image $\mathrm{J}$ (National Institutes of Health, USA) and Photoshop (Adobe Systems Software Ireland Ltd). All experiments were repeated three times.

\section{Electrolyte leakage assays}

Cell death of $N$. benthamiana was assayed by determining ion leakage from leaf discs as previously described [27]. For each sample, five leaf discs ( $8 \mathrm{~mm}$ diameter) were placed into a $10-\mathrm{ml}$ tube containing $5 \mathrm{ml}$ sterile and doubledistilled water for $3 \mathrm{~h}$ at room temperature (RT). Then the conductivity EC1 of the bathing solution was measured with a conductivity meter (DDS-307, Rex Shanghai, China). The conductivity EC2 of the solution was measured by boiling the sealed tubes for $25 \mathrm{~min}$ and then cooling to RT. Electrolyte leakage $(\%)=100 \times \mathrm{EC} 1 / \mathrm{EC} 2$. These experiments were repeated three times.

\section{Accession numbers}

All sequence information from this study can be found in GenBank data library of National Center for Biotechnology Information (NCBI) under accession numbers listed in Additional file 3: Table S2.

\section{Results}

RxLR16 from $P$. viticola induces cell death in $N$. benthamiana Our previous analysis identified 51 candidates RxLR effectors from $P$. viticola and only several putative effectors were tested for suppression of BAX- and INF1induced cell death [38]. To identify defense response elicitor proteins, we expressed all these RxLR proteins transiently by agroinfiltration of PVX vectors and assayed them for induction of cell death in $N$. benthamiana leaves. INF1 from $P$. infestans and AVR3a/R3a, which are known to induce cell death in $N$. benthamiana, were served as positive controls $[18,45]$. Of the 51 RxLR effectors, only PvRxLR16 developed a visible phenotype, inducing an HR in $N$. benthamiana $5 \mathrm{~d}$ after infiltration [39], showing the similar symptom to that induced by INF1 and AVR3a/R3a (Fig. 1a and b). As a negative control, no HR phenotypes were observed in the GFP-infiltrated leaves (Fig. 1a and b). We also expressed PvRxLR16 in Arabidopsis and tomato. However, expression of the PvRxLR16 did not trigger cell death in these two plant species (data not shown). These results demonstrated that PvRxLR16 may be recognized by an endogenous disease resistance protein, resulting in avirulence on $N$. benthamiana.

PvRxLR16 requires nuclear localization to trigger cell death To determine whether PvRxLR16 localize to nucleus in different plant species as in $N$. benthamiana [39], it was fused with the $\mathrm{N}$ terminus of GFP under the control of the CaMV $35 \mathrm{~S}$ promoter and transiently expressed in Arabidopsis protoplasts and onion epidermal cells. Result demonstrated that the green fluorescence almost completely accumulated in the nucleus of Arabidopsis protoplasts, while control GFP was detected in both cytoplasm and nucleus (Fig. 2a). When we transiently expressed the PvRxLR16-GFP fusion protein with the pH7FWG2,0 vector in onion epidermal cells, the PvRxLR16 protein was also located in nucleus (Fig. 2b). The combined results from these two experiments clearly concluded that PvRxLR16 localizes to nucleus.

To investigate whether the nuclear localization is required for PvRxLR16 to elicit cell death, a synthetic NES (nuclear exclusion signal) and a nes (nonfunctional NES) [46] were added to the C terminus of PvRxLR16, respectively. The fused proteins were ectopically expressed using agroinfiltration in $N$. benthamiana. PvRxLR16 ${ }^{\text {NES }}$, excluded from the nucleus, consistently failed to induce cell death at $5 \mathrm{dpi}$, while PvRxLR16 ${ }^{\text {nes }}$ robustly induced 

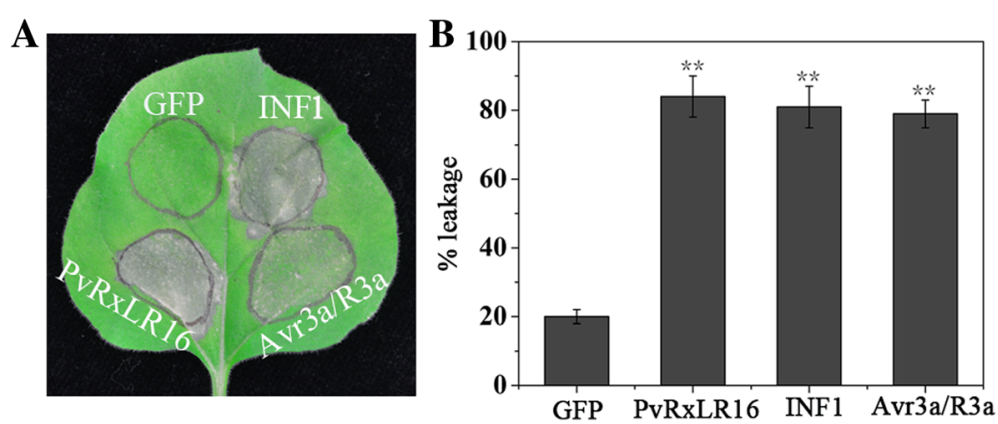

Fig. 1 PVRxLR16 induces cell death in N. benthamiana. a Leaves of $N$. benthamiana were infiltrated with $A$. tumefaciens carrying PVX-Flag::PVRxLR16 and the indicated controls. The photography was taken $5 \mathrm{~d}$ post infiltration. The experiment was repeated three times with similar results. $\mathbf{b}$ Quantification of cell death by measuring electrolyte leakage. Error bars represent standard errors from three biological replicates $\left(^{* *}, P<0.01\right.$, Dunnett's test)

cell death as the wild-type which retained in the nucleus (Fig. 2c and d). Thus, we inferred that nuclear localization is required for the triggering of cell death by PvRxLR16.

\section{Functional motifs of PvRxLR16}

Sequence analysis showed that full-length PvRxLR16 encodes a polypeptide of 265 amino acids with a predicted signal peptide (SP) (aa 1-18) and a RxLR-dEER motif (aa 46-61). In addition, PvRxLR16 was predicted to contain W/Y/L motifs using the HMMER v3.0 package [47]. To identify the potential functional motifs of PvRxLR16 for induction of cell death, deletion mutants of PvRxLR16 were analyzed using agroinfiltration in $N$. benthamiana. None of the deletion mutants but PvRxLR16-1, a mutant of RxLR-dEER motif deleted, could induce cell death (Fig. 3a). Immunoblot analysis showed that all deletion mutants of PvRxLR16 accumulated to comparable degrees in $N$. benthamiana leaves (Fig. 3b). These data demonstrated that all the W/Y/L motifs are required for inducing cell death.

Identification of putative $\mathrm{N}$-glycosylation sites required for the cell death-inducing activity of PvRxLR16.

Secreted proteins often undergo $N$-linked glycosylation which is one of the most ubiquitous posttranslational modifications. It has been reported that $N$-glycosylation is crucial for both the structure and function of effector proteins that play important roles in the pathogenesis of filamentous fungi [48]. Using NetNGlyc1.0 (available
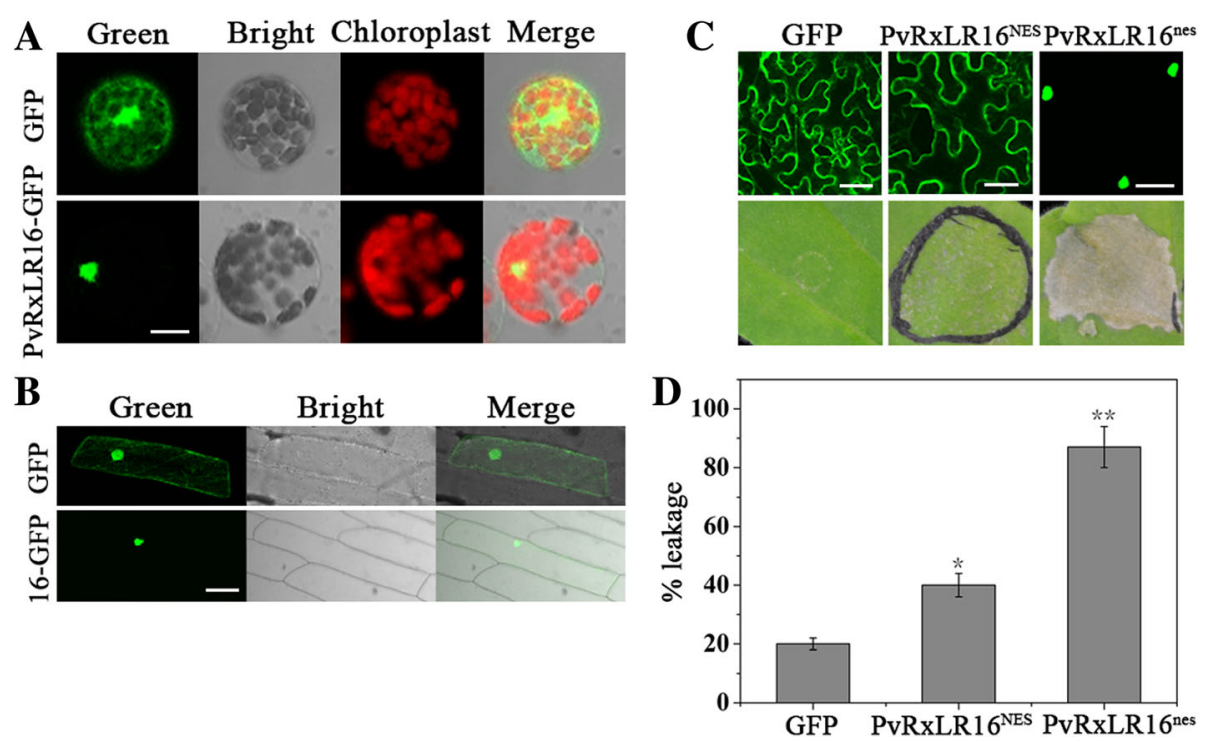

Fig. 2 PvRxLR16 effector domains function in plant nucleus. a Green fluorescence-tagged PvRxLR16 were transiently expressed in Arabidopsis protoplasts via PEG-mediated transformation approach. Scale bar $=25 \mu \mathrm{m}$. b GFP- PVRxLR16 fusion protein was expressed in onion epidermal cells. Scale bar $=50 \mu \mathrm{m}$. c Nuclear localization is required for PvRxLR16-triggering cell death. $N$. benthamiana leaves were agroinfiltrated with the indicated constructs $2 \mathrm{~d}$ and $5 \mathrm{~d}$ before assessment of GFP confocal imaging and cell death observation, respectively. NES and nes represent the nuclear export signal and nonfunctional NES. Scale bar $=20 \mu \mathrm{m}$. d Quantification of cell death by measuring electrolyte leakage. Error bars represent standard errors from three biological replicates ( ${ }^{* *}$ for $P<0.01$ and ${ }^{*}$ for $P<0.05$, Dunnett's test) 


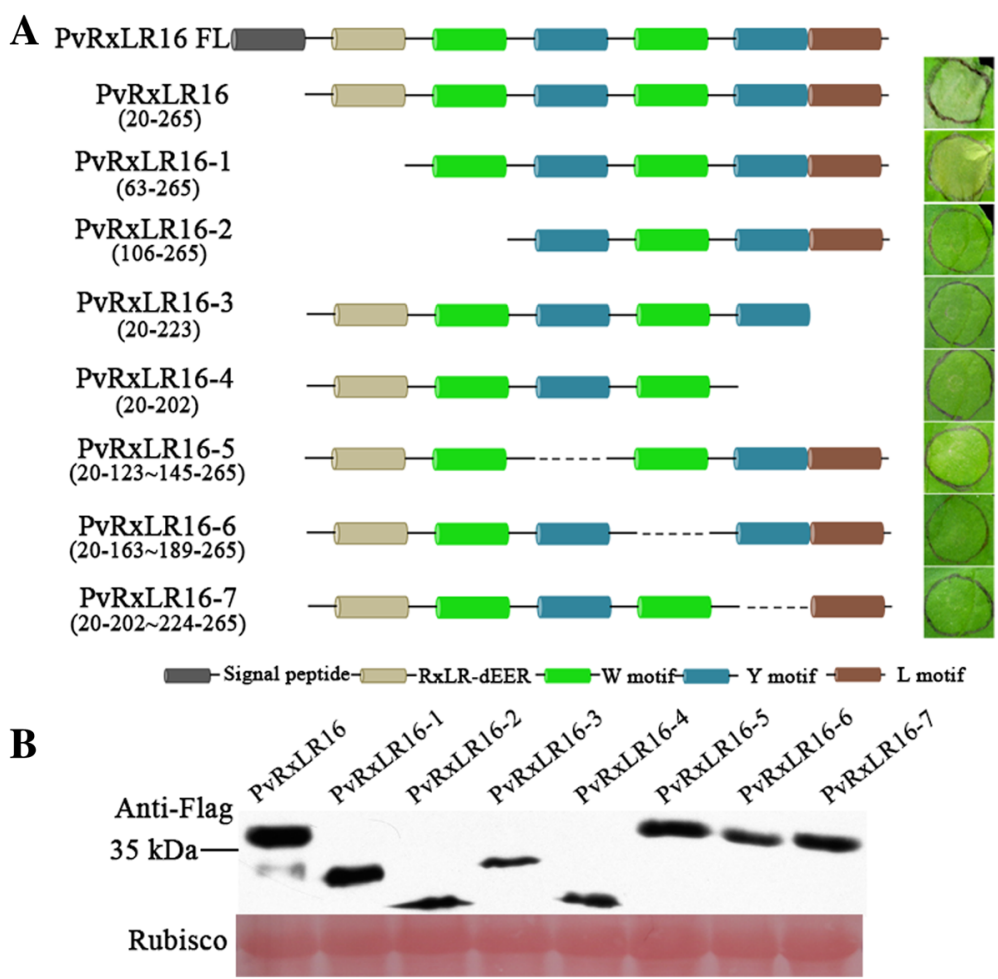

Fig. 3 Deletion analysis of PvRxLR16. a Left column, schematic diagrams of deletion mutants for PvRxLR16. Right column, deletion mutants of PVRXLR16 were expressed by agroinfiltration in N. benthamiana to investigate induction of cell death. The representative pictures were taken at 5 dpi. b Immunoblot analysis of proteins from $N$. benthamiana leaves transiently expressing PVRXLR16 and its deletion mutants from a PVX-3 $\times$ Flag vector

online at http://www.cbs.dtu.dk/services/NetNGlyc/), PvRxLR16 is predicted to be a glycoprotein with three putative $N$-glycosylation sites that are located at Asn-170 (NGSS), Asn-219 (NLTT) and Asn-240 (NEST). To establish their contribution to cell death-inducing activity, site-specific mutations were introduced into the three putative $N$-glycosylation sites in the PVXPvRxLR16-3xFLAG construct. Then they were transiently expressed in leaves of $N$. benthamiana. It is obvious that both PvRxLR16 ${ }^{\mathrm{N} 170 \mathrm{~A}}$ and PvRxLR16 ${ }^{\mathrm{N} 219 \mathrm{~A}}$ elicited visible cell death response as wild type PvRxLR16 five days after infiltration (Fig. 4a). Strikingly, PvRxLR16 ${ }^{\text {N240A }}$ could hardly induce any cell death symptoms (Fig. 4a). All mutations of PvRxLR16 were successfully expressed in $N$. benthamiana (Fig. 4b). Cell death was quantified by measurement of ion leakage [49] (Fig. 4c). This finding highlights the importance of this predicted $\mathrm{N}$ glycosylation site Asn-240 for the cell death-inducing activity of PvRxLR16.

PvRxLR16-triggered cell death in $N$. benthamiana depends on SGT1, Hsp90 and RAR1 but not Serk3/Bak1

It is known that SGT1, Hsp90 and RAR1 perform essential functions in $\mathrm{R}$ protein- mediated HR by regulating the stability of $\mathrm{R}$ protein complex $[50,51]$. The receptorlike kinase SERK3/BAK1 was identified as crucial factor in various PTI responses, including programmed cell death induction by INF1 [52]. To determine the involvement of SGT1, Hsp90, RAR1 and Serk3 in induction of cell death by PvRxLR16, we performed a VIGS assay against these genes in $N$. benthamiana. The silenced plants were then agroinfiltrated with PvRxLR16 or INF1. Results showed that PvRxLR16 failed to trigger cell death in SGT1-, Hsp90- and RAR1- silenced plants, whereas it was still capable of inducing cell death in Serk3-silenced plants (Fig. 5a and b). Reverse transcription- quantitative PCR (RT-qPCR) analysis confirmed that expressions of purpose genes were markedly reduced in silenced plants compared with pTV00, validating successful silencing (Fig. 5c). These results indicate that PvRxLR16-triggered cell death is dependent on SGT1, Hsp90 and RAR1, but independent of Serk3/Bak1.

\section{Involvement of mitogen-activated protein kinase (MAPK) cascades}

MAPK cascades play a remarkably important role in both PTI and ETI [53]. A series of kinases and transcription factors have been characterized that play an essential role in plant immunity and cell death induction during interactions between plants and pathogens, including mitogen-activated protein kinase kinase kinase (MAPKKK $\alpha)$, MAP kinase kinase 2 (MEK2), salicylic 


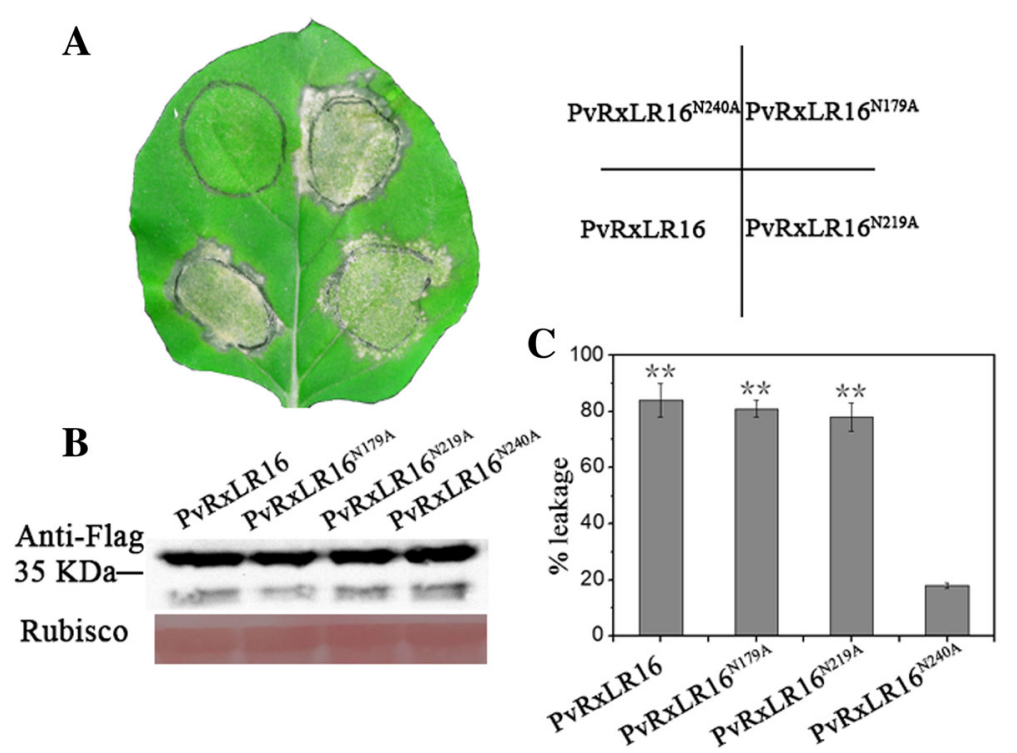

Fig. 4 Functional characterization of three putative N-glycosylation sites for PVRxLR16. a Expression of PVRxLR16 and its mutants in N. benthamiana by agroinfiltration. Typical symptoms were photographed at $5 \mathrm{dpi}$. $\mathbf{b}$ Immunoblot analysis of proteins from $\mathrm{N}$. benthamiana leaves transiently expressing PVRxLR16 and its site-specific mutations from a PVX-3 $\times$ Flag vector. c Quantification of cell death by measuring electrolyte leakage. Error bars represent standard errors from three biological replicates $\left(^{* *}, P<0.01\right.$, Dunnett's test)

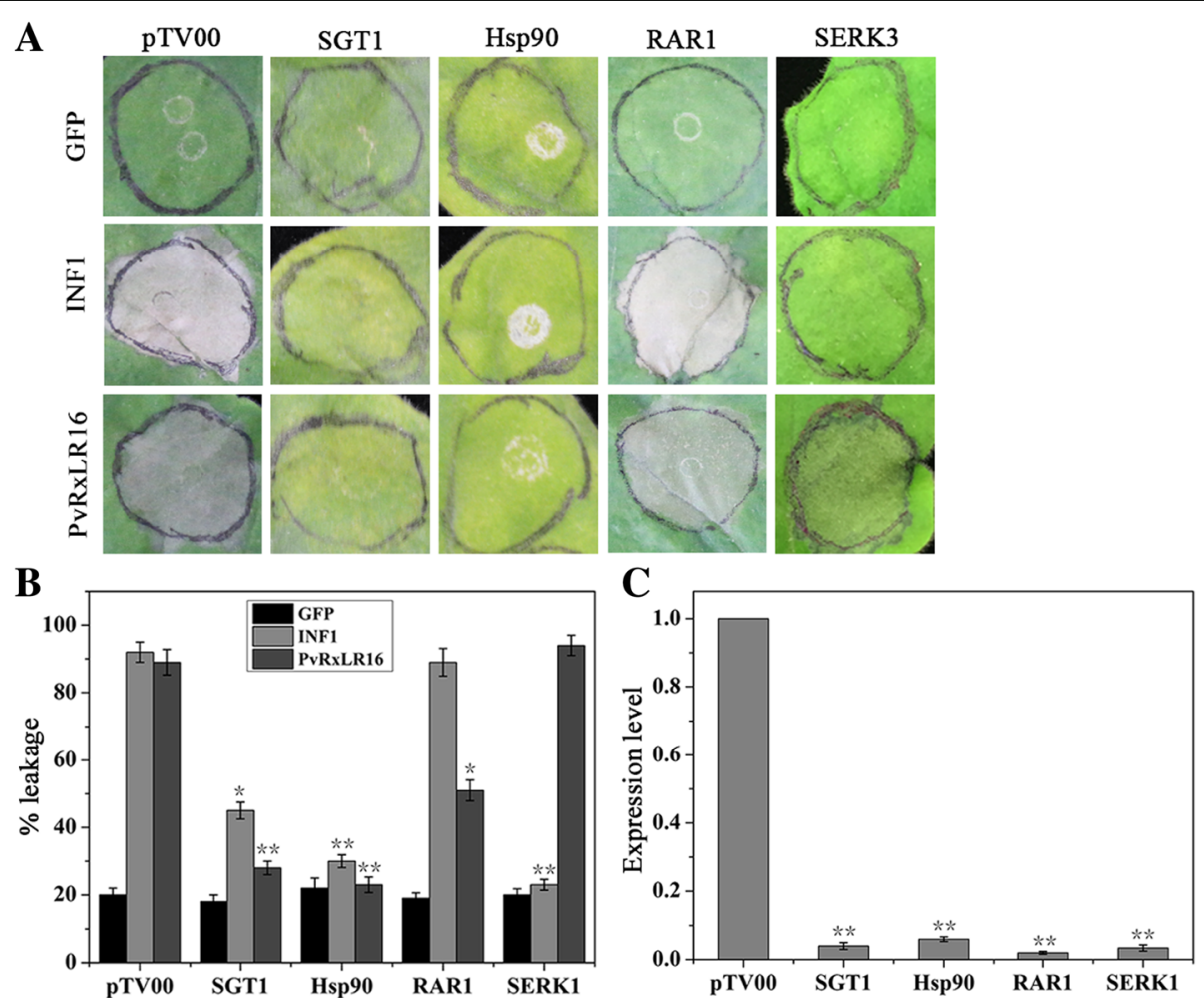

Fig. 5 SGT1, Hsp90, and RAR1 were required for PvRxLR16-induced cell death in N. benthamiana. a PvRxLR16 was transiently expressed in N. benthamiana leaves silenced for pTV00 (control), SGT1, Hsp90, RAR1, and SERK3. GFP and INF1 are control proteins. Typical symptoms were photographed after $5 \mathrm{~d}$ after agroinfiltration. b Quantification of cell death by measuring electrolyte leakage. Averages and standard errors were calculated from three independent experimental treatments ( ${ }^{* *}$ for $P<0.01$ and ${ }^{*}$ for $P<0.05$, Dunnett's test). $\mathbf{c}$ Transcript levels of indicated genes in silenced $N$. benthamiana measured by quantitative RT-PCR. Error bars represent standard errors from three biological replicates ( ${ }^{* *}, P<0.01$, Dunnett's test) 
acid-induced protein kinase (SIPK), MAP kinase kinase 1 (MEK1), NTF6, wound-induced protein kinase (WIPK), WRYK1 and WRKY2 [54-56]. To investigate the possible roles of these proteins in PvRxLR16induced cell death, each of them was silenced in $N$. benthamiana via VIGS and challenged with PvRxLR16 effector. INF1 was chosen as a positive control which triggers cell death independently of these kinases and transcription factors. Cell death was compromised in plants silenced for all genes with one exception (WIPK) (Fig. 6a and b). Figure $6 \mathrm{c}$ showed the transcript abundances of purpose genes in the silenced $N$. benthamiana, validating successful silencing. These results suggest that most mitogen-activated protein kinases and transcription factors tested in this study are involved in the perception of PvRxLR16 by N. benthamiana.

\section{PvRxLR16 induces disease resistance in N. benthamiana and promotes ROS accumulation}

To determine whether PvRxLR16 could activate other defense responses in $N$. benthamiana, plants were agroinfiltrated separately with PvRxLR16, PvRxLR16 ${ }^{\text {NES }}$, or PvRxLR16 ${ }^{\text {nes }}$, and GFP was used as a control. The final concentration of Agrobacterium suspension was adjusted to an $\mathrm{OD}_{600}$ of 0.2 which could not induce cell death at $2.5 \mathrm{~d}$ post-infiltration (Additional file 4: Figure S2). And then $24 \mathrm{~h}$ later, the infiltrated regions were inoculated with $P$. capsici zoospores and disease development was evaluated by measuring lesion diameter of disease at 36 hpi. Disease symptoms became visible on leaves agroinfiltrated with GFP expression constructs, which was similar to PvRxLR16 ${ }^{\mathrm{NES}}$, whereas PvRxLR16 and PvRxLR16 ${ }^{\text {nes }}$-infiltrated leaves were protected against pathogen infection (Fig. 7a). Determination of P. capsici lesion diameter (Fig. 7b) revealed that PvRxLR16 and PvRxLR16 ${ }^{\text {nes }}$ decreased $P$. capsici growth significantly.

To explore mechanisms behind the increased disease resistance of PvRxLR16, the production of $\mathrm{H}_{2} \mathrm{O}_{2}$ in infected leaves was analysed using the diaminobenzidine (DAB) staining. The relative staining was significantly higher in infected regions of PvRxLR16 and PvRxLR16 ${ }^{\text {nes }}$ compared to that in the PvRxLR16 ${ }^{\text {NES }}$ and GFP control (Fig. 7c and d), indicating that PvRxLR16 needs to target the plant nucleus to promote $\mathrm{H}_{2} \mathrm{O}_{2}$ accumulation. Taken together, these data showed that PvRxLR16 requires nuclear localization to activate plant defenses and prevent colonization of the pathogen.

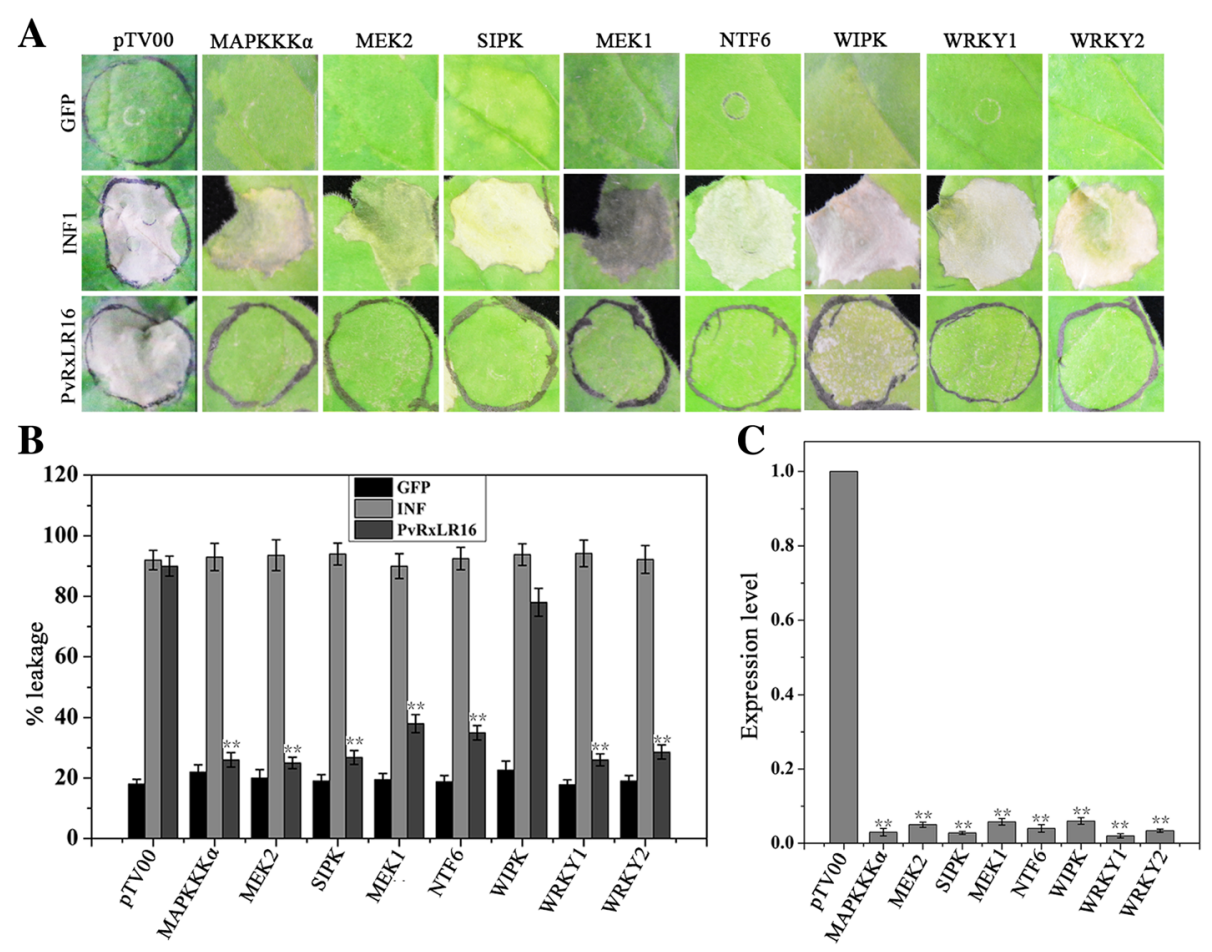

Fig. 6 MAPK cascades were required for PVRXLR16-induced cell death in N. benthamiana. a PvRxLR16 was transiently expressed in $N$. benthamiana leaves silenced for indicated MAPK cascades genes. GFP and INF1 are control proteins. Typical symptoms were photographed after $5 \mathrm{~d}$ after agroinfiltration. b Quantification of cell death by measuring electrolyte leakage. Averages and standard errors were calculated from three independent experimental treatments $\left(^{* *}, P<0.01\right.$, Dunnett's test). c Transcript levels of indicated genes in silenced $N$. benthamiana measured by quantitative RT-PCR. Error bars represent standard errors from three biological replicates $\left(^{* *}, P<0.01\right.$, Dunnett's test) 


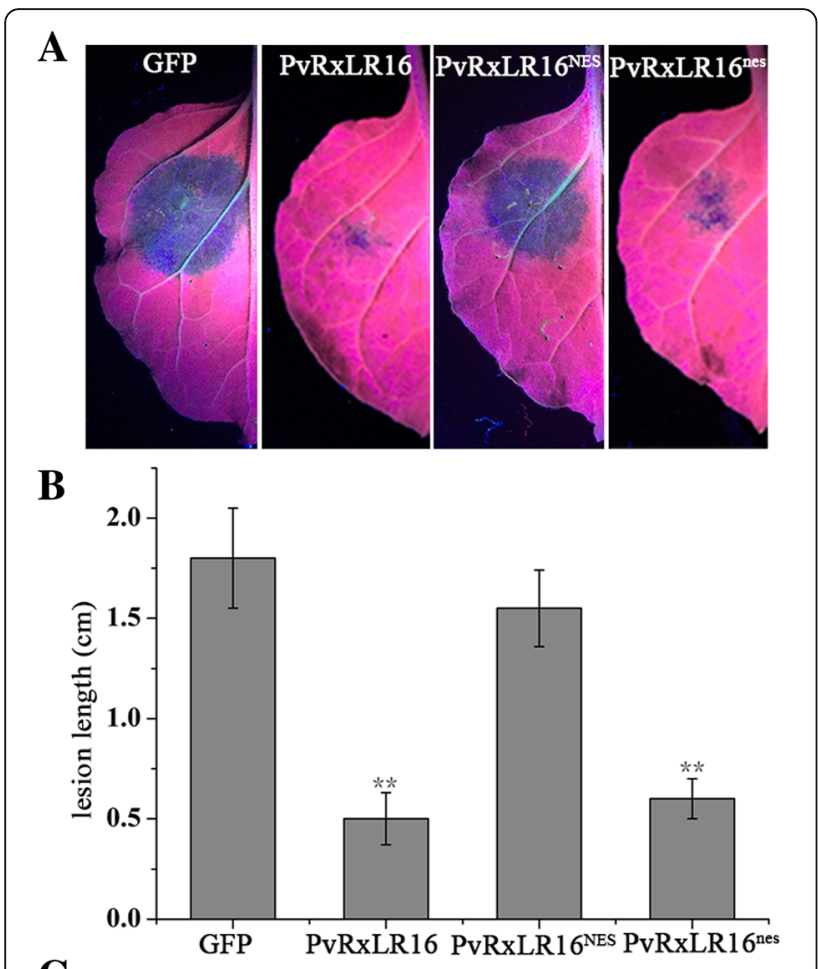

C

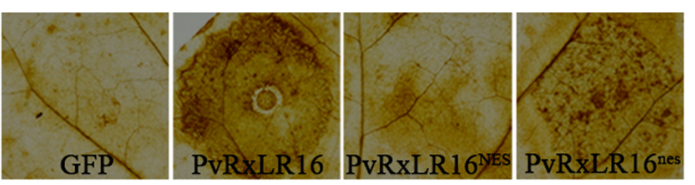

D

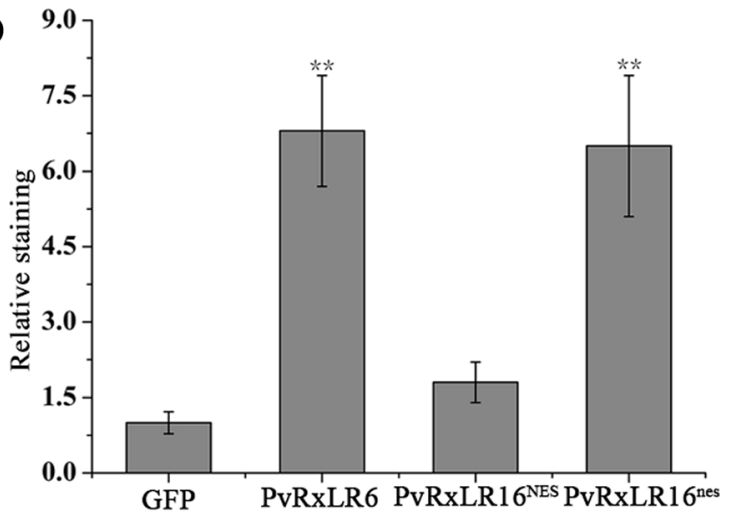

Fig. 7 Introduction of disease resistance and $\mathrm{H}_{2} \mathrm{O}_{2}$ accumulation by PVRxLR16 in N. benthamiana. a Lesions of the $N$. benthamiana leaves expressing the indicated genes inoculated with $P$. capsici at 36 hpi. $\mathbf{b}$ Lesion diameters of $N$. benthamiana leaves ( ${ }^{* *} P<0.01$, Dunnett's test). c DAB staining of the $N$. benthamiana leaves at 3 dpi expressing the indicated genes. $\mathbf{d}$ The relative levels of DAB staining. Asterisks indicate significant differences ( ${ }^{* *} P<0.01$, Dunnett's test). These experiments were replicated three times with six leaves per biological replicate

PvRxLR16 enhances the expression of defence-associated genes in N. benthamiana

To increase our understanding of the role of PvRxLR16 in plant defense responses, transcriptional levels of defencerelated genes were analysed using real time qRT-PCR.
Since salicylic acid (SA)-, jasmonate acid (JA)-, and ethylene (ET)-mediated signal transduction pathways play critical roles in disease resistance to pathogens [57], expression levels of marker genes for each pathway were analysed. The PR1a/PR2b, ERF1 and $L O X$ are marker genes for salicylate-, ethylene- and jasmonate -mediated signaling pathway, respectively [58-60]. Expression levels of these defence-related genes were significantly upregulated in the leaves transiently expressing PvRxLR16 compared to GFP (Fig. 8). These results suggest that expression of PvRxLR16 may enhance the expressional levels of defence-associated genes in $N$. benthamiana, resulting in disease resistance.

\section{PvRxLR16-triggered immunity can be suppressed by other PvRxLR effectors}

Although individual effectors can trigger strong defense responses, some other RxLR effectors are capable of inhibiting defense responses including effector- triggered immunity [61]. Previous data have shown that most PvRxLRs tested can suppress cell death induced by PvRxLR16 [39]. To further determine whether PvRxLR16induced defense responses in addition to cell death could also be repressed by PvRxLR effectors, we assayed whether disease resistance, ROS production and defencerelated genes activated by PvRxLR16 could be repressed by transiently expressing $P v R x L R 1, P v R x L R 10, P v R x L R 30$ and $P v R x L R 25$ in $N$. benthamiana. The leaves were infiltrated with PvRxLR16 constructs $12 \mathrm{~h}$ after expressing each PvRxLR or GFP using agroinfiltration. ROS accumulation was detected by staining of leaves $72 \mathrm{~h}$ after expressing PvRxLR16. For disease development assay, the infiltrated leaves were inoculated with $P$. capsici zoospores $\left(10 \mu \mathrm{l}, 100\right.$ zoospores $\left.\mu \mathrm{l}^{-1}\right)$, and lesion diameter of disease was measured at 36 hpi. Results demonstrated that PvRxLR1, PvRxLR10 and PvRxLR30 suppressed PvRxLR16 induced disease resistance (Fig. 9a and c) and ROS accumulation (Fig. 9b and d) compared with negative control PvRxLR25 and GFP. QRT-PCR analysis revealed that these three PvRxLRs could also reduce the introduction of defence-related genes by PvRxLR16 to some extent (Fig. 9e). Therefore, the defense responses of $N$. benthamiana elicited by PvRxLR16 could be efficiently repressed by other PvRxLR effectors.

\section{Discussion}

In plant-pathogen interactions, RxLR effectors play a vital role in the establishment of pathogen infection and also conversely a role in plant defense [26]. In recent years, hundreds of RxLR effectors were predicated in various oomycete pathogen species via genome sequencing or RNA-seq [25, 38, 62-66]. Large-scale functional surveys of candidate RxLR effectors from $P$. infestans, $P$. sojae and $H$. arabidopsidis revealed that majority of 

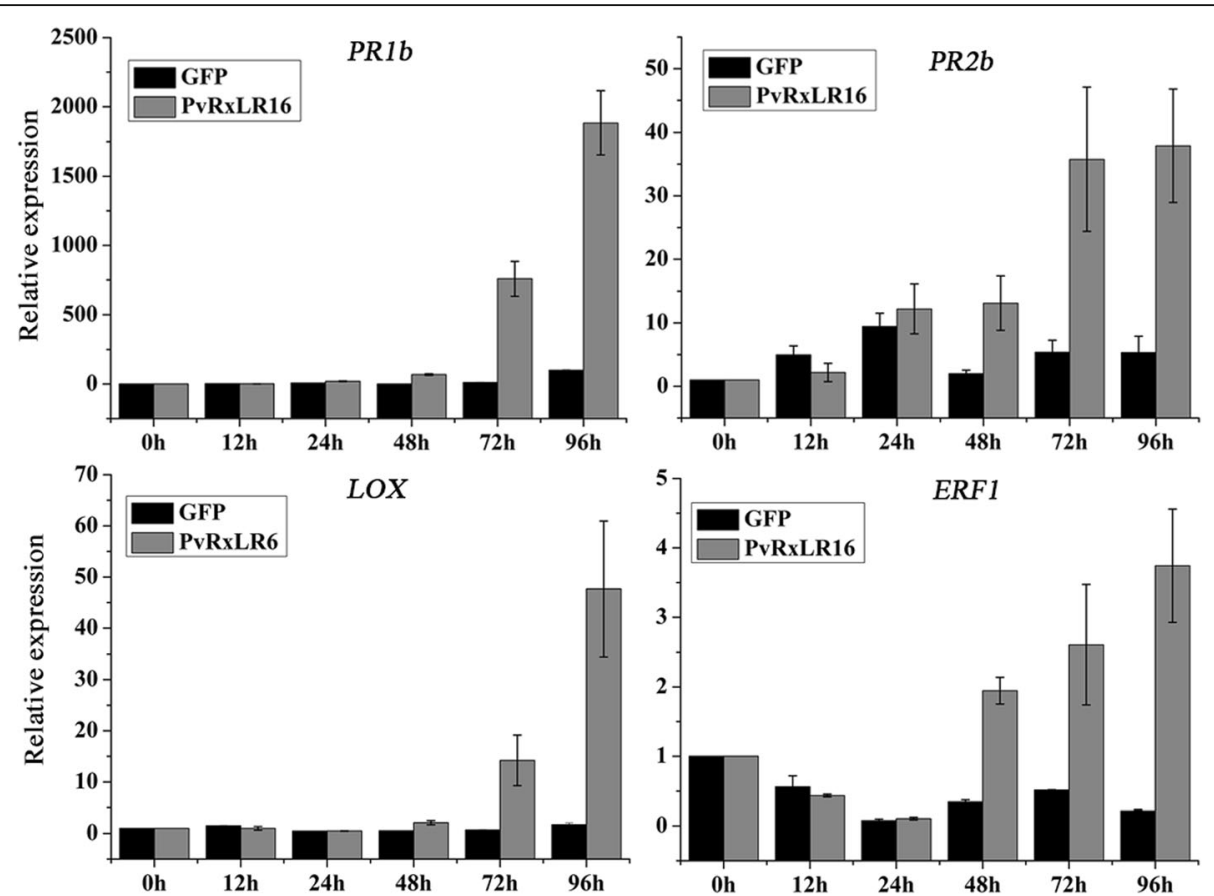

Fig. 8 Upregulation of defense- related genes mediated by PVRXLR16 in N. benthamiana. Transcript level of the PR1b, PR2b, LOX and ERF1 genes induced by PvRxLR16 at different time points. Means and standard errors from three independent replicates are shown

them could suppress cell death and immunity, whereas a few could trigger cell death or immune responses $[21,61,67]$. Some cell death-inducing effectors, such as PsAvh163 and PsAvh241 from P. sojae, have been proven to activate ETI or PTI in plant $[27,68]$. The candidate effector PvRxLR16 was identified as the only one that can elicit cell death in $N$. benthamiana in a survey of $P$. viticola effectors [39]. Here we also demonstrate that it also induce other immune responses in addition to cell death. The defense responses triggered by PvRxLR16 has the potential to block infection of $N$. benthamiana by $P$. capsici, while in the mean time, other PvRxLR effectors have the capacity to suppress the PvRxLR16-triggered immune responses.

The species specific cell death and disease resistance induction of PvRxLR16 indicates that it seems to function as a typical avirulence protein in $N$. benthamiana. PvRxLR16 could still trigger cell death in BAK1 (Serk3)-silenced N. benthamiana, indicating that it acts independently of the detection of cell surface pattern recognition receptors. However, triggering of cell death in $N$. benthamiana requires SGT1, HSP90 and RAR1, suggesting that PvRxLR16-dependent cell death may result from ETI rather than non-specific toxicity of PvRxLR16. Additionally, silencing of MAPK and transcription factor genes indicated that PvRxLR16-induced cell death requires all tested genes with one exception, WIPK, which is required for transducing signals from the PAMP receptor flagellin-sensitive 2 (FLS2) [27].
Collectively, we speculate that PvRxLR16 may targets an upstream component of plant ETI pathway, possibly an endogenous $\mathrm{R}$ protein. The endogenous protein responsible for the detection may have evolved to recognize homologous genes of PvRxLR16 in a downy mildew pathogen of Nicotiana species (e.g. Peronospora tabacina Adam).

A growing body of evidence indicates that plant cell nucleus is a main target for oomycete pathogen effectors. A recent study that investigated the subcellular localization patterns of $H$. arabidopsidis RxLR effector candidates in planta found that $66 \%$ RxLR effectors could target the host cell nucleus [28]. Moreover, functional analysis of CRN effectors from Phytophthora confirmed that majority of them target the nucleus [40,69, 70]. The authors showed that alteration of nuclear targeting signals in several CRN effectors prevented their cell death-inducing activities. In this study, we demonstrated that nuclear localization of PvRxLR16 is required to induce cell death and defence responses. A similar case was reported in $P$. infestans where the avirulence factor AVR1 has also to be present in nucleus to activate $R$ gene-mediated resistance [35]. Therefore, it is reasonable to believe that the nucleus localization of PvRxLR16 is essential for endogenous proteins recognition, resulting in immune responses.

Effector-triggered immunity (ETI) is generally associated with pathogen resistance, induction of ROS burst, ion influx, and increased expression levels of defence-related genes [71]. In this study, we observed that transient 
A

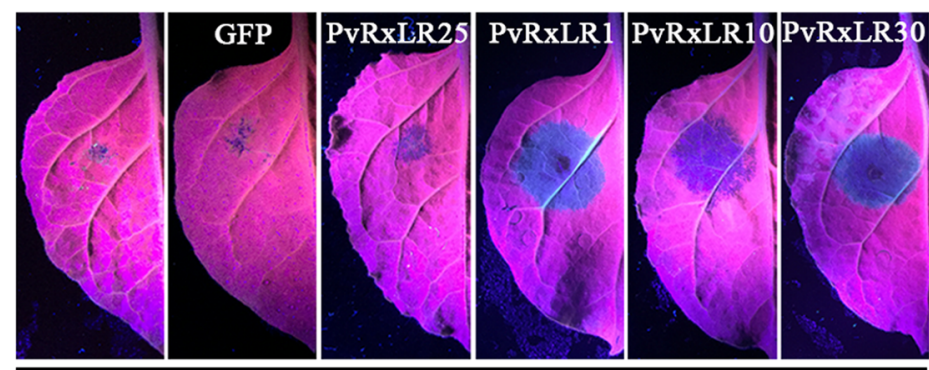

PvRxLR16

B

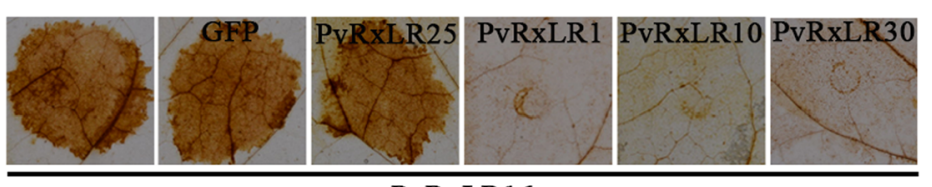

PvRxLR16

C

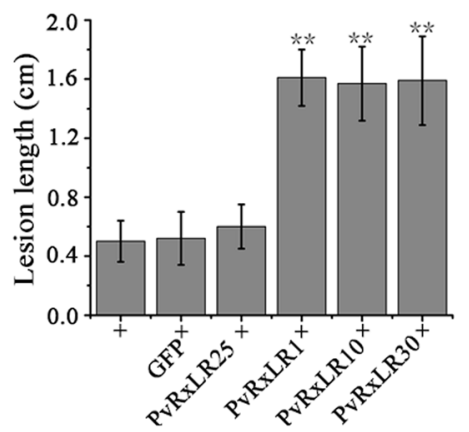

$\mathbf{E}$

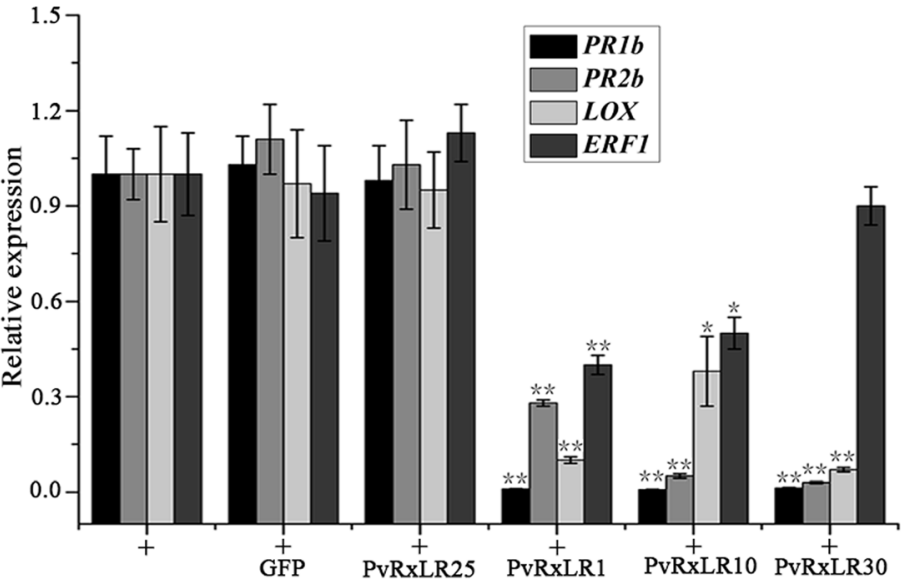

Fig. 9 Suppression of PVRXLR16-induced disease resistance and immune responses by PVRXLR effectors in N. benthamiana. a Lesions of the N. benthamiana leaves expressing the indicated genes inoculated with P. capsici at 36 hpi. The leaves were infiltrated with PVRxLR16 constructs $12 \mathrm{~h}$ after expressing each PVRxLR or GFP using agroinfiltration. Then the infiltrated leaves were inoculated with $P$. capsici $48 \mathrm{~h}$ after expression of PvRxLR16. The representative pictures were taken at 36 hpi post infection of $P$. capsici. b DAB staining of the N. benthamiana leaves at 3 dpi expressing PVRxLR16. PVRxLR effectors (PVRxLR1, 10 and 30) and GFP were transiently expressed in N. benthamiana leaves by agroinfiltration $12 \mathrm{~h}$ before infiltration of PvRxLR16. $\mathbf{c}$ Lesion diameters of $N$. benthamiana leaves (**P $<0.01$, Dunnett's test). $\mathbf{d}$ The relative levels of DAB staining. Significant differences based on Dunnett's test are indicated by the asterisks ( $\left.{ }^{* *} P<0.01\right)$. These experiments were replicated three times with six leaves per biological replicate. e Relative expression levels of PR1b, PR2b, LOX, and ERF1 genes induced by PvRxLR16 were suppressed by other PvRxLRs (PvRxLR1, 10 and 30) in N. benthamiana. PvRxLR effectors (PvRxLR1, 10 and 30) and GFP were transiently expressed in N. benthamiana leaves by agroinfiltration $12 \mathrm{~h}$ before infiltration of PVRxLR16. The relative transcript levels of defense-related genes were detected at $3 \mathrm{dpi}$ expressing PvRxLR16 (+). EF1a was used as an endogenous control. Means and standard errors from three independent replicates are shown. Significant differences based on Dunnett's test are indicated by the asterisks $\left({ }^{*} P<0.01,{ }^{*} P<0.05\right.$ ) 
expression of the PvRxLR16 in N. benthamiana enhanced resistance against $P$. capsici, and also ROS accumulation and expression level of defence-related genes were increased. These defence responses were consistent with ETI. It is worth noting that SA, JA and ET signaling pathways were all activated by PvRxLR16 effector. It is plausible that PvRxLR16 could elicit multiple defense pathways to restrict pathogen growth. SA, JA and ET are the classical immunity hormones which play key roles in plant defenses against pathogens. SA signaling is generally crucial for immunity against biotrophs or hemibiotrophs, while JA and ET signaling are often important for immunity against necrotrophs, although there are exceptions [57]. It will be very interesting to determine whether PvRxLR16-induced immunity can inhibit invasion of different pathogens to $N$. benthamiana.

Although plants have the ability to detect and respond to RxLR effectors, successful pathogens have clearly evolved sophisticated mechanisms to surmount the immune responses of hosts [72]. Interference with PTI and ETI by effectors secreted by pathogens has been reported in multiple systems [34]. A complex repertoire of candidate RxLR effectors was identified from $P$. viticola, and expression pattern of which could be grouped into four main groups. Eighteen PvRxLR effectors from each of the different expression profile groups could suppress cell death induced by PvRxLR16 in N. benthamiana with several exceptions [39]. All of these RxLR effectors could also inhibit cell death induced by BAX, INF1, PsojNIP, PsCRN63 and Avr3a/R3a, indicating that they all may target a common pathway that mediates plant cell death and defense responses. Several of these effectors, particularly $P v R x L R 1, P v R x L R 10$, and $P v R x L R 30$, were expressed mediumly or highly during early infection and showed similar expression pattern as PvRxLR16 [39], suggesting that these RxLR effectors may act preemptively to inhibit the capability of hosts to respond to PvRxLR16. However, these effectors could not suppress PvRxLR16-triggered immune responses when PvRxLR16 is already highly expressed in plant, prior to induction of these three RxLR effectors (data not shown). Thus, the capability of plants to respond to the PvRxLR16 will probably place an upper limit on the expression level of the effector by $P$. viticola. Isolation of $P v R x L R 16$ from several physiological races of $P$. viticola revealed no sequence polymorphism in $P v R x L R 16$ (data not shown). Unexpectedly, this effector does not appear to be under diversifying selection though it can induce cell death and defence responses in $N$. benthamiana. It is currently unknown whether PvRxLR16 can activate cell death under natural conditions in its host, grapevine. PvRxLR16 may possibly not trigger cell death during physiological infection, alleviating selection pressure for changes in itself. Unfortunately, since $P$. viticola can hardly be genetically modified because of its typical obligate lifestyle, it is difficult to determine whether PvRxLR16 is essential for the pathogenicity of $P$. viticola during infection.

\section{Conclusions}

This is the first study to report that a putative RxLR effector from $P$. viticola is recognized by the plant immune system and even may act as an avirulence gene in $N$. benthamiana. The ability of PvRxLR16 to trigger cell death will be very useful to exploit ATTA (Agrobacterium tumefaciens-mediated transient expression), VIGS or other tools in N.benthamiana. Moreover, it may be also used for identifying novel defence related genes against $P$. viticola or other oomycetes which will be pivotal for providing insights into novel disease control strategies.

\section{Additional files}

Additional file 1: Table S1. Primers used in this study. (DOCX $24 \mathrm{~kb}$ )

Additional file 2: Figure S1. Schematic diagrams of constructs used in this study. (TIFF $1018 \mathrm{~kb}$ )

Additional file 3: Table S2. Genbank accession numbers of genes in N. benthamiana and PVRXLR effectors used in this study. (DOCX $14 \mathrm{~kb}$ )

Additional file 4: Figure S2. Transient expression of PvRxLR16 and GFP in $N$. benthamiana. Representative $N$. benthamiana leaves infiltrated with various concentrations $\left(\mathrm{OD}_{600}=0.4,0.2,0.1\right)$ of Agrobacterium suspension containing the PVX-PVRXLR16 or PVX-GFP. Upper pictures, directly photographed $2.5 \mathrm{~d}$ post-infiltration. Lower pictures, photographed $2.5 \mathrm{~d}$ post-infiltration after staining with trypan blue. (TIFF $1612 \mathrm{~kb}$ )

\section{Abbreviations}

ATTA: Agrobacterium tumefaciens-mediated transient expression; Avr: Avirulence; DAB: 3, 3'- diaminobenzidine; DTT: Dl-dithiothreitol; EDTA: ethylenediaminetetraacetate; ET: Ethylene; ETI: Effector-triggered immunity; ETS: Effector-triggered susceptibility; FLS2: Flagellin-sensitive 2; GFP: Green fluorescent protein; HEPES: 4-(2-hydroxyethyl)-1-

piperazineëthanesulfonic acid; HR: Hypersensitive response; HSP90: Heat shock protein 90; JA: Jasmonate acid; LB: Luria-Bertani; MAPK: Mitogenactivated protein kinase; MAPKKKa: Mitogen-activated protein kinase kinase kinase; MEK1: MAP kinase kinase 1; MEK2: MAP kinase kinase 2; MS: Murashige-Skoog; NCBI: National Center for Biotechnology Information; nes: nonfunctional nuclear exclusion signal; NES: Nuclear exclusion signal; PAMPS/ MAMPs: Pathogen- or microbe-associated molecular patterns; PCD: Programmed cell death; PRRs: Pattern recognition receptors; PTI: PAMPtriggered immunity; RAR1: Required for Mla12 resistance; ROS: Reactive oxygen species; SA: Salicylic acid; SDS-PAGE: Sodium dodecyl sulfate-polyacrylamide gel electrophoresis; SERK3: Somatic embryogenesis receptor-like kinase; SGT1: Suppressor of G-two allele of Skp1; SIPK: Salicylic acid-induced protein kinase; SP: Signal peptide; TAIR: The Arabidopsis Information Resource; VIGS: Virus induced gene silencing; WIPK: Wound-induced protein kinase

\section{Acknowledgements}

We are very grateful to Profs. Daqi Fu (China Agricultural University), Yuanchao Wang and Daolong Dou (Nanjing Agricultural University) for providing materials and technical support.

\section{Funding}

This work was supported by National Natural Science Foundation of China (grant no. 31471754), China Agriculture Research System (grant no. CARS-30-yz-2) and the Start-up Fund from Shanghai Jiaotong University (WF107115001). 


\section{Availability of data and materials}

The datasets generated or analyzed during the current study are available from the corresponding author on reasonable request. Sequence data from this study can be found in NCBI's GenBank data library (https:// www.ncbi.nlm.nih.gov/) under accession numbers listed in additional files.

\section{Authors' contributions}

All authors have confirmed their contribution, read and approved this manuscript. Conceived and designed the experiments: JX, XLL, LY, YLZ, JL. Performed the experiments: JX, XLL, YXL, JJQ. Analyzed the data: JX, LY, JL. Wrote the manuscript: JX, JL.

\section{Competing interests}

The authors declare that they have no competing interests.

\section{Consent for publication}

Not applicable.

\section{Ethics approval and consent to participate}

Not applicable.

\section{Publisher's Note}

Springer Nature remains neutral with regard to jurisdictional claims in published maps and institutional affiliations.

\section{Author details}

${ }^{1}$ The Viticulture and Enology Program, College of Food Science and Nutritional Engineering, China Agricultural University, Beijing, China. ${ }^{2}$ Center for Viticulture and Enology, School of Agriculture and Biology, Shanghai Jiao Tong University, Shanghai 200240, China. ${ }^{3}$ Guangxi Crop Genetic Improvement and Biotechnology Laboratory, Guangxi Academy of Agricultural Sciences, Nanning, China.

\section{Received: 20 October 2016 Accepted: 23 March 2017}

\section{Published online: 14 April 2017}

\section{References}

1. Jones DA, Takemoto D. Plant innate immunity-direct and indirect recognition of general and specific pathogen-associated molecules. Curr Opin Immunol. 2004;16(1):48-62.

2. Nürnberger T, Brunner F, Kemmerling B, Piater L. Innate immunity in plants and animals: striking similarities and obvious differences. Immunol Rev. 2004;198(1):249-66.

3. Chisholm ST, Coaker G, Day B, Staskawicz BJ. Host-microbe interactions: shaping the evolution of the plant immune response. Cell. 2006;124(4):803-14.

4. Jones JD, Dangl JL. The plant immune system. Nature. 2006;444(7117):323-9.

5. Dodds PN, Rathjen JP. Plant immunity: towards an integrated view of plantpathogen interactions. Nat Rev Genet. 2010;11(8):539-48.

6. Dangl JL, Jones JD. Plant pathogens and integrated defence responses to infection. Nature. 2001:411(6839):826-33.

7. May K, Whisson S, Zwart R, Searle I, Irwin J, Maclean D, Carroll B, Drenth A. Inheritance and mapping of 11 avirulence genes in Phytophthora sojae. Fungal Genet Biol. 2002;37(1):1-12.

8. Erwin DC, Ribeiro OK. Phytophthora diseases worldwide. St Paul: American Phytopathological Society (APS Press); 1996.

9. Clark J, Spencer-Phillips P. Downy mildews. Encyclopaedia of microbiology 2000;2:117-29.

10. Tyler BM. Entering and breaking: virulence effector proteins of oomycete plant pathogens. Cell Microbiol. 2009;11(1):13-20.

11. Shan W, Cao M, Leung D, Tyler BM. The Avrib locus of Phytophthora sojae encodes an elicitor and a regulator required for avirulence on soybean plants carrying resistance gene Rps 16. Mol Plant-Microbe Interact. 2004; 17(4):394-403.

12. Dong S, Qutob D, Tedman-Jones J, Kuflu K, Wang Y, Tyler BM, Gijzen M. The Phytophthora sojae avirulence locus Avr3c encodes a multi-copy RXLR effector with sequence polymorphisms among pathogen strains. PLoS One. 2009;4(5):e5556.

13. Qutob D, Tedman-Jones J, Dong S, Kuflu K, Pham H, Wang Y, Dou D, Kale SD, Arredondo FD, Tyler BM. Copy number variation and transcriptional polymorphisms of Phytophthora sojae RXLR effector genes Avrla and Avr3a. PLoS One. 2009;4(4):e5066.
14. Dou D, Kale SD, Liu T, Tang Q, Wang X, Arredondo FD, Basnayake S, Whisson S, Drenth A, Maclean D. Different domains of Phytophthora sojae effector Avr $4 / 6$ are recognized by soybean resistance genes Rps 4 and Rps 6. Mol Plant-Microbe Interact. 2010;23(4):425-35.

15. Dong S, Yin W, Kong G, Yang X, Qutob D, Chen Q, Kale SD, Sui Y, Zhang Z, Dou D. Phytophthora sojae avirulence effector Avr3b is a secreted NADH and ADP-ribose pyrophosphorylase that modulates plant immunity. PLoS Pathog. 2011;7(11):e1002353.

16. Dong S, Yu D, Cui L, Qutob D, Tedman-Jones J, Kale SD, Tyler BM, Wang Y, Gijzen M. Sequence variants of the Phytophthora sojae RXLR effector Avr3a/ 5 are differentially recognized by Rps3a and Rps 5 in soybean. PLoS One. 2011;6(7):20172.

17. Song T, Kale SD, Arredondo FD, Shen D, Su L, Liu L, Wu Y, Wang Y, Dou D, Tyler BM. Two RxLR avirulence genes in Phytophthora sojae determine soybean Rps 1k-mediated disease resistance. Mol Plant-Microbe Interact. 2013;26(7):711-20.

18. Armstrong MR, Whisson SC, Pritchard L, Bos Jl, Venter E, Avrova AO, Rehmany AP, Böhme U, Brooks K, Cherevach I. An ancestral oomycete locus contains late blight avirulence gene Avr3a, encoding a protein that is recognized in the host cytoplasm. Proc Natl Acad Sci U S A. 2005;102(21):7766-71.

19. van Poppel PM, Guo J, van de Vondervoort PJ, Jung MW, Birch PR, Whisson SC, Govers F. The Phytophthora infestans avirulence gene Avr4 encodes an RXLR-dEER effector. Mol Plant-Microbe Interact. 2008;21(11):1460-70.

20. Vleeshouwers V, Rietman H, Krenek P, Champouret N, Young C, Oh S-K, Wang M, Bouwmeester K, Vosman B, Visser RG. Effector genomics accelerates discovery and functional profiling of potato disease resistance and Phytophthora infestans avirulence genes. PLoS One. 2008;3(8):e2875.

21. Oh S-K, Young C, Lee M, Oliva R, Bozkurt TO, Cano LM, Win J, Bos JI, Liu H-Y, van Damme M. In planta expression screens of Phytophthora infestans RXLR effectors reveal diverse phenotypes, including activation of the Solanum bulbocastanum disease resistance protein Rpi-blb2. Plant Cell. 2009;21 (9):2928-47.

22. Allen RL, Bittner-Eddy PD, Grenville-Briggs L, Meitz JC, Rehmany AP, Rose LE, Beynon JL. Host-parasite coevolutionary conflict between Arabidopsis and downy mildew. Science. 2004;306(5703):1957-60.

23. Rehmany AP, Gordon A, Rose LE, Allen RL, Armstrong MR, Whisson SC, Kamoun S, Tyler BM, Birch PR, Beynon JL. Differential recognition of highly divergent downy mildew avirulence gene alleles by RPP1 resistance genes from two Arabidopsis lines. Plant Cell. 2005;17(6):1839-50.

24. Bailey K, Çevik V, Holton N, Byrne-Richardson J, Sohn KH, Coates M, WoodsTör A, Aksoy HM, Hughes L, Baxter L. Molecular cloning of ATR5Emoy2 from Hyaloperonospora arabidopsidis, an avirulence determinant that triggers RPP5-mediated defense in Arabidopsis. Mol Plant-Microbe Interact. 2011; 24(7):827-38.

25. Jiang RH, Tripathy S, Govers F, Tyler BM. RXLR effector reservoir in two Phytophthora species is dominated by a single rapidly evolving superfamily with more than 700 members. Proc Natl Acad Sci. 2008;105(12):4874-9.

26. Anderson RG, Deb D, Fedkenheuer K, McDowell JM. Recent progress in RXLR effector research. Mol Plant-Microbe Interact. 2015;28(10):1063-72.

27. Yu X, Tang J, Wang Q, Ye W, Tao K, Duan S, Lu C, Yang X, Dong S, Zheng $X$, et al. The RxLR effector Avh241 from Phytophthora sojae requires plasma membrane localization to induce plant cell death. New Phytol. 2012;196(1):247-60.

28. Caillaud M-C, Piquerez SJM, Fabro G, Steinbrenner J, Ishaque N, Beynon J, Jones JDG. Subcellular localization of the Hpa RxLR effector repertoire identifies a tonoplast-associated protein HaRxL17 that confers enhanced plant susceptibility. Plant J. 2012;69(2):252-65.

29. Bozkurt TO, Schornack S, Win J, Shindo T, llyas M, Oliva R, Cano LM, Jones AM, Huitema E, van der Hoorn RA. Phytophthora infestans effector AVRblb2 prevents secretion of a plant immune protease at the haustorial interface. Proc Natl Acad Sci. 2011;108(51):20832-7.

30. Saunders DG, Breen S, Win J, Schornack S, Hein I, Bozkurt TO, Champouret N, Vleeshouwers VG, Birch PR, Gilroy EM. Host protein BSL1 associates with Phytophthora infestans RXLR effector AVR2 and the Solanum demissum immune receptor R2 to mediate disease resistance. Plant Cell. 2012;24(8):3420-34.

31. Wang X, Boevink P, McLellan H, Armstrong M, Bukharova T, Qin Z, Birch PR. A Host KH RNA-Binding Protein Is a Susceptibility Factor Targeted by an RXLR Effector to Promote Late Blight Disease. Mol Plant. 2015;8(9):1385-95.

32. Boevink $P C$, Wang $X$, McLellan $H$, He Q, Naqvi S, Armstrong MR, Zhang W, Hein I, Gilroy EM, Tian Z. A Phytophthora infestans RXLR effector targets plant PP1C isoforms that promote late blight disease. Nat Commun. 2016;7: 10311. doi:10.1038/ncomms10311. 
33. Qutob D, Kemmerling B, Brunner F, Küfner I, Engelhardt S, Gust AA, Luberacki B, Seitz HU, Stahl D, Rauhut T. Phytotoxicity and innate immune responses induced by Nep1-like proteins. Plant Cell. 2006;18(12):3721-44.

34. Thomma BP, Nürnberger T, Joosten MH. Of PAMPs and effectors: the blurred PTI-ETI dichotomy. Plant Cell. 2011;23(1):4-15.

35. Du Y, Berg J, Govers F, Bouwmeester K. Immune activation mediated by the late blight resistance protein $\mathrm{R} 1$ requires nuclear localization of $\mathrm{R} 1$ and the effector AVR1. New Phytol. 2015;207(3):735-47.

36. Liu Z-Q, Qiu A-L, Shi L-P, Cai J-S, Huang X-Y, Yang S, Wang B, Shen L, Huang M-K, Mou S-L. SRC2-1 is required in PCINF1-induced pepper immunity by acting as an interacting partner of PcINF1. J Exp Bot. 2015;66(13):3683-98.

37. Gessler C, Pertot I, Perazzolli M. Plasmopara viticola: a review of knowledge on downy mildew of grapevine and effective disease management. Phytopathol Mediterr. 2011;50(1):3-44.

38. Yin L, Li X, Xiang J, Qu J, Zhang Y, Dry IB, Lu J. Characterization of the secretome of Plasmopara viticola by de novo transcriptome analysis. Physiol Mol Plant Pathol. 2015;91:1-10.

39. Xiang J, Li X, Wu J, Yin L, Zhang Y, Lu J. Studying the mechanism of Plasmopara viticola RxLR effectors on suppressing plant immunity. Front Microbiol. 2016;7:709.

40. Mafurah JJ, Ma H, Zhang M, Xu J, He F, Ye T, Shen D, Chen Y, Rajput NA, Dou D. A virulence essential CRN effector of Phytophthora capsici suppresses host defense and induces cell death in plant nucleus. PLoS One. 2015;10(5):e0127965

41. Yoo S-D, Cho Y-H, Sheen J. Arabidopsis mesophyll protoplasts: a versatile cell system for transient gene expression analysis. Nat Protoc. 2007;2(7): $1565-72$.

42. Mare C, Mazzucotelli E, Crosatti C, Francia E, Cattivelli L. Hv-WRKY38: a new transcription factor involved in cold-and drought-response in barley. Plant Mol Biol. 2004;55(3):399-416.

43. Wu J, Zhang Y, Zhang H, Huang H, Folta KM, Lu J. Whole genome wide expression profiles of Vitis amurensis grape responding to downy mildew by using Solexa sequencing technology. BMC Plant Biol. 2010;10(1):234.

44. Thordal-Christensen $H$, Zhang Z, Wei Y, Collinge DB. Subcellular localization of $\mathrm{H}_{2} \mathrm{O}_{2}$ in plants. $\mathrm{H}_{2} \mathrm{O}_{2}$ accumulation in papillae and hypersensitive response during the barley_-powdery mildew interaction. Plant J. 1997; 11(6):1187-94.

45. Kamoun S, van West P, Vleeshouwers VG, de Groot KE, Govers F. Resistance of Nicotiana benthamiana to Phytophthora infestans is mediated by the recognition of the elicitor protein INF1. Plant Cell. 1998;10(9):1413-25.

46. Shen Q-H, Saijo Y, Mauch S, Biskup C, Bieri S, Keller B, Seki H, Ülker B, Somssich IE, Schulze-Lefert P. Nuclear activity of MLA immune receptors links isolate-specific and basal disease-resistance responses. Science. 2007; 315(5815):1098-103.

47. Finn RD, Clements J, Eddy SR. HMMER web server: interactive sequence similarity searching. Nucleic Acids Res. 2011;39:W29-W37.

48. Chen X-L, Shi T, Yang J, Shi W, Gao X, Chen D, Xu X, Xu J-R, Talbot NJ, Peng $Y$-L. N-glycosylation of effector proteins by an a-1, 3-mannosyltransferase is required for the rice blast fungus to evade host innate immunity. Plant Cell. 2014;26(3):1360-76.

49. Mittler R, Herr EH, Orvar BL, Van Camp W, Willekens H, Inzé D, Ellis BE. Transgenic tobacco plants with reduced capability to detoxify reactive oxygen intermediates are hyperresponsive to pathogen infection. Proc Natl Acad Sci. 1999;96(24):14165-70.

50. Shirasu K, Schulze-Lefert P. Complex formation, promiscuity and multifunctionality: protein interactions in disease-resistance pathways. Trends Plant Sci. 2003;8(6):252-8.

51. Shirasu K. The HSP90-SGT1 chaperone complex for NLR immune sensors. Annu Rev Plant Biol. 2009;60:139-64.

52. Heese A, Hann DR, Gimenez-Ibanez S, Jones AM, He K, Li J, Schroeder JI, Peck SC, Rathjen JP. The receptor-like kinase SERK3/BAK1 is a central regulator of innate immunity in plants. Proc Natl Acad Sci. 2007;104(29): 12217-22.

53. Pitzschke A, Schikora A, Hirt H. MAPK cascade signalling networks in plant defence. Curr Opin Plant Biol. 2009;12(4):421-6.

54. Zhang H, Li D, Wang M, Liu J, Teng W, Cheng B, Huang Q, Wang M, Song W, Dong S. The Nicotiana benthamiana mitogen-activated protein kinase cascade and WRKY transcription factor participate in nep1Mo-triggered plant responses. Mol Plant-Microbe Interact. 2012;25(12):1639-53.

55. Menke FL, Kang H-G, Chen Z, Park JM, Kumar D, Klessig DF. Tobacco transcription factor WRKY1 is phosphorylated by the MAP kinase SIPK and mediates HR-like cell death in tobacco. Mol Plant-Microbe Interact. 2005; 18(10):1027-34.

56. del Pozo O, Pedley KF, Martin GB. MAPKKKa is a positive regulator of cell death associated with both plant immunity and disease. EMBO J. 2004; 23(15):3072-82.

57. Glazebrook J. Contrasting mechanisms of defense against biotrophic and necrotrophic pathogens. Annu Rev Phytopathol. 2005;43:205-27.

58. Lee S, Ishiga Y, Clermont K, Mysore KS. Coronatine inhibits stomatal closure and delays hypersensitive response cell death induced by nonhost bacterial pathogens. PeerJ. 2013;1:e34.

59. Lorenzo O, Piqueras R, Sánchez-Serrano JJ, Solano R. ETHYLENE RESPONSE FACTOR1 integrates signals from ethylene and jasmonate pathways in plant defense. Plant Cell. 2003;15(1):165-78.

60. Wang C, Zien CA, Afitlhile M, Welti R, Hildebrand DF, Wang X. Involvement of phospholipase $D$ in wound-induced accumulation of jasmonic acid in Arabidopsis. Plant Cell. 2000;12(11):2237-46.

61. Wang Q, Han C, Ferreira AO, Yu X, Ye W, Tripathy S, Kale SD, Gu B, Sheng Y, Sui $Y$, et al. Transcriptional Programming and Functional Interactions within the Phytophthora sojae RXLR Effector Repertoire. Plant Cell. 2011;23(6):2064-86.

62. Tyler BM, Tripathy S, Zhang X, Dehal P, Jiang RH, Aerts A, Arredondo FD, Baxter L, Bensasson D, Beynon JL. Phytophthora genome sequences uncover evolutionary origins and mechanisms of pathogenesis. Science. 2006; 313(5791):1261-6.

63. Haas BJ, Kamoun S, Zody MC, Jiang RH, Handsaker RE, Cano LM, Grabherr M, Kodira CD, Raffaele S, Torto-Alalibo T. Genome sequence and analysis of the Irish potato famine pathogen Phytophthora infestans. Nature. 2009; 461(7262):393-8

64. Baxter L, Tripathy S, Ishaque N, Boot N, Cabral A, Kemen E, Thines M, AhFong A, Anderson R, Badejoko W. Signatures of adaptation to obligate biotrophy in the Hyaloperonospora arabidopsidis genome. Science. 2010; 330(6010):1549-51.

65. Savory EA, Zou C, Adhikari BN, Hamilton JP, Buell CR, Shiu S-H, Day B. Alternative splicing of a multi-drug transporter from Pseudoperonospora cubensis generates an RXLR effector protein that elicits a rapid cell death. PLoS One. 2012;7(4):e34701.

66. Sharma R, Xia X, Cano LM, Evangelisti E, Kemen E, Judelson H, Oome S, Sambles C, van den Hoogen DJ, Kitner M. Genome analyses of the sunflower pathogen Plasmopara halstedii provide insights into effector evolution in downy mildews and Phytophthora. BMC Genomics. 2015;16(1):741.

67. Fabro G, Steinbrenner J, Coates M, Ishaque N, Baxter L, Studholme DJ, Körner E, Allen RL, Piquerez SJ, Rougon-Cardoso A. Multiple candidate effectors from the oomycete pathogen Hyaloperonospora arabidopsidis suppress host plant immunity. PLoS Pathog. 2011;7(11):e1002348.

68. Anderson RG, Casady MS, Fee RA, Vaughan MM, Deb D, Fedkenheuer K, Huffaker A, Schmelz EA, Tyler BM, McDowell JM. Homologous RXLR effectors from Hyaloperonospora arabidopsidis and Phytophthora sojae suppress immunity in distantly related plants. Plant J. 2012;72(6):882-93.

69. Schornack S, van Damme M, Bozkurt TO, Cano LM, Smoker M, Thines M, Gaulin E, Kamoun S, Huitema E. Ancient class of translocated oomycete effectors targets the host nucleus. Proc Natl Acad Sci. 2010;107(40):17421-6.

70. Liu T, Ye W, Ru Y, Yang X, Gu B, Tao K, Lu S, Dong S, Zheng X, Shan W. Two host cytoplasmic effectors are required for pathogenesis of Phytophthora sojae by suppression of host defenses. Plant Physiol. 2011;155(1):490-501.

71. Cui H, Tsuda K, Parker JE. Effector-triggered immunity: from pathogen perception to robust defense. Annu Rev Plant Biol. 2015;66:487-511.

72. Yin W, Dong S, Zhai L, Lin Y, Zheng X, Wang Y. The Phytophthora sojae Avr1d gene encodes an RxLR-dEER effector with presence and absence polymorphisms among pathogen strains. Mol Plant-Microbe Interact. 2013;26(8):958-68 